$\underline{\text { Reports }}$

\title{
Leveraging digital platforms for disseminating health and nutrition information during COVID-19: reflections from Project Samvad in India
}

\author{
Farhad Ali', Sanjay Kumar Paswan', Gelsey Bennett ${ }^{2}$, Ronali Pradhan³ ${ }^{3}$ S B Nadagouda ${ }^{4}$, Sanjukta Roy Choudhury \\ ${ }^{1}$ Digital Green, New Delhi, India, ${ }^{2}$ Digital Green, Washington DC, USA, ${ }^{3}$ Digital Green, Bhubaneshwar, Odisha, India, 4 Digital Green, Patna, Bihar, \\ India, 5 Digital Green, Kolkata, India \\ Keywords: health information, india, rmnch, covid-19
}

https://doi.org/10.29392/001c.22121

Journal of Global Health Reports

Vol. 5, 2021

\begin{abstract}
Countries around the globe, including India, are making strides to combat maternal and child health issues. To support these efforts, Digital Green implemented Project Samvad, a USAID-funded reproductive, maternal, newborn, and child health (RMNCH) project working across six states in India. The project used a human-mediated community video approach to improve maternal and child health outcomes. In early 2020 , due to mobility-related restrictions and norms related to physical distancing resulting from the COVID-19 pandemic, Project Samvad's field activities stalled. This descriptive study highlights the project's pivot to the use of digital tools to reach beneficiaries during the COVID-19 pandemic. The project delivered COVID-19 related information by layering it on the existing RMNCH messages. It used WhatsApp and Interactive Voice Response System to reach out to the community and frontline workers. The content of the messages was locally relevant, culturally appropriate, and addressed the concerns of the local community concerning their immediate needs related to RMNCH and COVID-19. The project recorded a listenership of 85,199 and a content viewership of 283,866 in three months. The initiative also oriented 918 frontline workers virtually on their roles and responsibilities during COVID-19. The insights from the adaptation of our approach in the context of COVID-19 can help project managers and policymakers address communication issues during the pandemic or any other emergency, using digital dissemination for reaching beneficiaries, building the capacities of partners, engaging community members and frontline workers for improved learning, and dealing with process-related challenges.
\end{abstract}

Although countries around the globe are making strides to combat maternal and child health issues, India is still lagging. While the maternal mortality ratio in India fell from 370 to 145 between 2000 and 2017, ${ }^{1}$ state-specific variations in the country remain due to geographical vastness, sociocultural diversity, and the performance of health systems in different states. ${ }^{2}$ Approximately 1.5 million children under the age of five die annually in India, with 800,000 newborn children losing their lives within 28 days of their birth. ${ }^{3}$ Project Samvad, funded by the U.S. Agency for International Development (USAID) and implemented by Digital Green, has been working over the last six years to improve maternal and child health outcomes through the promotion of appropriate family planning methods and nutrition messaging using locally relevant video content meant and understandable for and by the communities. These videos are shared with women in the reproductive age group (15-34 years old) during in-person village-level meetings using pocket-sized projectors. Frontline workers (FLW) conducting door-to-door community visits identify these women and approach them to join these village meetings.
At the onset of the 2019 novel coronavirus (COVID-19) pandemic, the Indian Government declared a nationwide lockdown, impacting Project Samvad's ability to disseminate community videos on reproductive, maternal, newborn, and child health (RMNCH) during these in-person village-level meetings. The project team hypothesized that the project could continue reaching out to the community with RMNCH messages and support the FLW using digital platforms such as WhatsApp and Integrated Voice Response System (IVRS). Project Samvad leaned into its past experiments and institutional experience with technology to redesign its approach and actively use digital tools to reach beneficiaries and continue serving the RMNCH sector. While this would require training FLW and the buy-in of the partners, we believed that we could use digital tools to bring FLW up to speed and quickly repurpose messaging to ensure continuity of support to the community. Furthermore, we recognized that the risk of stopping the RMNCH messaging was too high and could negatively affect maternal and child health outcomes in particular as the health sector in India focuses more intensively on combating the pandemic. This descriptive study highlights the project's pivot to the use 
of digital tools to reach beneficiaries during the COVID-19 pandemic.

\section{METHODS}

Project Samvad undertook the following methodology for the development and rollout of the plan to use digital tools to disseminate RMNCH and COVID-19 messaging: (i) First, we conducted small groups interviews with stakeholders involved in the development and rollout of the initiative; (ii) next, we conducted internal discovery workshops with the core team that developed and rolled out the digital approach; (iii) and finally, we kept thorough notes of the process, reviewing and analyzing data as we had it available.

\section{THE PROCESS OF PROGRAM DEVELOPMENT AND ROLLOUT}

Knowing that videos could no longer be shared in in-person group settings, to respond to the emerging COVID-19 pandemic and ongoing needs related to RMNCH, Project Samvad began actively using digital tools to reach beneficiaries. The project repurposed existing RMNCH community videos and audio messages and layered COVID-19 prevention messaging. Messages were shortened and aligned with the needs of digital platforms such as IVRS and WhatsApp, to allow for swiftly sharing this content.

Project Samvad staff knew about the documented evidence that suggests that the use of information and communication technology can help in reaching out to the rural and remote communities to improve health information of the people, ${ }^{4}$ and as a result, felt comfortable in testing an all-digital approach. According to the Telecom Regulatory Authority of India, there are approximately 600 million internet subscribers in India as of 2019 , with $38 \%$ of these users are from rural India. ${ }^{5} \mathrm{~A}$ recent report reveals that there are 340 million WhatsApp users in India as of January $2020 .^{6}$ Although the access to phones by rural women is poor compared to urban women and also compared to their households, the data about the increased penetration of technology in rural communities gave us the confidence to progress with a digital approach for health communication during the onset of the pandemic. A survey conducted after the rollout of the digital tools at the project locations by Digital Green suggested that $66 \%$ of community members (both men and women) have smartphones, $10 \%$ have phones with WhatsApp operating systems, and 10\% have feature phones that can run WhatsApp. This data suggested that over $70 \%$ community members can access videos using WhatsApp and rest can get information through IVRS over their feature phones.

\section{ENGAGING PARTNERS}

While managing the project's continuity at the field level during the pandemic was challenging, project activities were able to successfully move forward with the support of our partners. The project reached out to our partner organizations and discussed using virtual platforms for video and audio dissemination. After a series of discussions, the partners agreed to the use of virtual channels for the dis- semination of the RMNCH videos and audio content layered with COVID-19 information. Their concerns were related to staff training needs, infrastructure, and ability to reach out to the community using these channels. Their concerns were addressed by assuring them to tackle many of these issues in the course of implementation by providing remote support, sharing of training resources, and building on the available infrastructure.

\section{USE OF DIGITAL PLATFORMS UNDER PROJECT SAMVAD DURING COVID-19}

FLW played a critical community role in sharing videos and messaging in the in-person group gatherings. To reach out to the community during the pandemic, Project Samvad used its partners' network of FLW at various levels, using mobile phones and social media platforms. WhatsApp groups were created at various levels including villages, sub-districts, districts, and the state level. The videos and the audio clips to be shared for dissemination were meticulously reviewed and selected by Digital Green and Project Samvad staff and experts from the partner organizations. Thereafter, these selected videos and audio clips were shared with the district and block level teams. The content was shared with the teams every week using the WhatsApp groups. The district and the block lead received the videos and then they shared them with their respective FLW and/or with the Accredited Social Health Activists (ASHA) lead persons. The district and the block lead maintained the list and names of the FLW/ASHA with whom the videos were shared. FLW/ASHA then shared the videos directly with the beneficiaries through the WhatsApp groups or on their individual WhatsApp numbers, followed by questions to generate engagement.

To track and monitor the viewership, the FLW and ASHA maintained the list of beneficiaries and produced short reports of how many people viewed the videos. The list, along with the report, was then shared with their respective block or district leads. The information in the report was then compiled at the district and state levels to ascertain the cumulative reach and viewership of the videos.

For IVRS, the partners shared lists with the mobile phone numbers of FLW and women (pregnant women and lactating mothers). These mobile phone numbers were used to send the automated outbound calls every week as per an agreed content calendar delineating the topics of messages and their timelines. The IVRS server-generated automated reports of the outbound call and also inbound calls by those who called back the system to ask questions and share feedback.

The details of the communication package are described in tables one and two. Table three provides the YouTube links of the audio and video content used as part of this digital approach.

\section{MONITORING AND EVALUATION}

For effective monitoring and course correction of Project Samvad's change in approach, data were collected using the manual system of reach and viewership and also the data that was extracted from the IVRS server every week. A 
Table 1: Videos repurposed and used during the COVID-19

\begin{tabular}{|c|c|c|c|c|}
\hline Category & \multicolumn{2}{|c|}{$\begin{array}{l}\text { Number of videos } \\
\text { repurposed and language }\end{array}$} & Issues covered & $\begin{array}{l}\text { Dissemination } \\
\text { channel used }\end{array}$ \\
\hline $\begin{array}{l}\text { Maternal and child } \\
\text { health }\end{array}$ & $\begin{array}{l}\text { Chhattisgarhi } \\
\text { Hindi } \\
\text { Odia } \\
- \text { Total }^{-}\end{array}$ & $\begin{array}{l}02 \\
04 \\
06 \\
12\end{array}$ & $\begin{array}{l}\text { - Importance of } 1000 \text { days } \\
\text { - } \\
\text { - Iron folic acid (IFA) supplementation } \\
\text { during pregnancy } \\
\text { - Oral rehydration solution (ORS) in di- } \\
\text { arrhea management }\end{array}$ & $\begin{array}{l}\text { WhatsApp mobile } \\
\text { phone screening }\end{array}$ \\
\hline Nutrition & 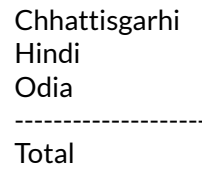 & $\begin{array}{l}01 \\
04 \\
04 \\
09\end{array}$ & $\begin{array}{l}\text { - Diet diversity during pregnancy } \\
\text { - Early and exclusive breastfeeding } \\
\text { - Complementary feeding and age-spe- } \\
\text { - } \quad \text { cific complementary feeding } \\
\text { - }\end{array}$ & $\begin{array}{l}\text { WhatsApp mobile } \\
\text { phone screening }\end{array}$ \\
\hline Family planning & $\begin{array}{l}\text { Chhattisgarhi } \\
\text { Hindi } \\
\text { Odia } \\
\text { Total }\end{array}$ & $\begin{array}{l}01 \\
02 \\
02 \\
05\end{array}$ & $\begin{array}{l}\text { - Importance of family planning } \\
\text { - Basket of choices and interspousal } \\
\text { communication }\end{array}$ & $\begin{array}{l}\text { WhatsApp mobile } \\
\text { phone screening }\end{array}$ \\
\hline $\begin{array}{l}\text { Frontline workers } \\
\text { (FLW) orientation }\end{array}$ & $\begin{array}{l}\text { Chhattisgarhi } \\
\text { Hindi } \\
\text { Odia } \\
---{ }^{-} \\
\text {Total }\end{array}$ & $\begin{array}{l}01 \\
03 \\
02 \\
06\end{array}$ & $\begin{array}{l}\text { - Role of frontline workers (FLW) during } \\
\text { the pandemic } \\
\text { - Do's and don'ts } \\
\text { - Use of WhatsApp for information dis- } \\
\text { semination } \\
\text { - How to use Samvad Interactive Voice } \\
\text { Response System (IVRS) }\end{array}$ & $\begin{array}{l}\text { WhatsApp mobile } \\
\text { phone screening }\end{array}$ \\
\hline
\end{tabular}

Note: All the video material was layered with COVID-19 precautionary measures to include information on avoiding touching eye, nose, and mouth, use of mask, physical distancing, and regular hand washing. It also covered information on special care to be taken during breastfeeding and feeding a baby.

Table 2: The list of audio material repurposed and used during the COVID-19

\begin{tabular}{|c|c|c|c|}
\hline Category & $\begin{array}{l}\text { Number of repurposed audios } \\
\text { and language }\end{array}$ & Issues covered & $\begin{array}{l}\text { Dissemination channel } \\
\text { list }\end{array}$ \\
\hline $\begin{array}{l}\text { Maternal and } \\
\text { child health }\end{array}$ & $\begin{array}{ll}\text { Hindi } & 04 \\
\text { Odia } & 04 \\
---- & 08\end{array}$ & $\begin{array}{l}\text { - Importance of } 1000 \text { days } \\
\text { - Antenatal care check-ups } \\
\text { - Iron folic acid (IFA) during pregnancy } \\
\text { - Handwashing } \\
\text { - Management of diarrhea and oral rehy- } \\
\text { dration solution (ORS) use }\end{array}$ & $\begin{array}{l}\text { Interactive Voice } \\
\text { Response System }\end{array}$ \\
\hline Nutrition & \begin{tabular}{ll} 
Hindi & 04 \\
Odia & 04 \\
\hdashline---- \\
Total & 08
\end{tabular} & $\begin{array}{l}\text { - } \quad \text { Diet diversity during pregnancy } \\
\text { - Early and exclusive breastfeeding } \\
\text { - } \quad \text { Complementary feeding } \\
\text { - } \text { Age-appropriate feeding }\end{array}$ & $\begin{array}{l}\text { Interactive Voice } \\
\text { Response System }\end{array}$ \\
\hline Family planning & $\begin{array}{ll}\text { Hindi } & 01 \\
\text { Odia } & 01 \\
- \text { Total }^{-} & 02\end{array}$ & $\begin{array}{l}\text { - Significance of family planning } \\
\text { - } \text { Modern contraceptive methods } \\
\text { - Inter-spousal communication }\end{array}$ & $\begin{array}{l}\text { Interactive Voice } \\
\text { Response System }\end{array}$ \\
\hline
\end{tabular}

Note: All the audio material was layered with COVID-19 precautionary measures to include information on avoiding touching eye, nose, and mouth, use of mask, physical distancing, and regular hand washing. It also covered information on special care to be taken during breastfeeding and feeding a baby.

weekly report was generated to monitor the program reach in terms of the number of people reached, viewership and listenership achieved, and the health workers oriented. The team met at weekly intervals to review the results to date and take appropriate actions.

\section{RESULTS AND DISCUSSION}

WhatsApp and IVRS helped in reaching communities with the RMNCH messages layered with the information on COVID-19 prevention and preparedness. During this time, messages were circulating on social media platforms with misinformation on the spread and prevention of COVID-19. ${ }^{7}$ Project Samvad's approach helped bust the myths and helped the health system to circulate correct and complete information on COVID-19 that was from the authentic source and was vetted by the sector experts. Project Samvad's change in approach helped in continuing the RM- 
Table 3: Audio and video library developed in different languages

\begin{tabular}{|l|l|l|}
\hline $\begin{array}{l}\text { Audio/ } \\
\text { video }\end{array}$ & Language & YouTube Link \\
\hline Video & Chhattisgarhi & $\begin{array}{l}\text { https://www.youtube.com/watch?v=pNObLcGQ7Rs\&list=PL- } \\
\text { WsPIITg__71zpbeZnnBE56wUuGEMzVe }\end{array}$ \\
\hline Video & Hindi & $\begin{array}{l}\text { https://www.youtube.com/watch?v=ewQa4m86CIY\&list=PL- } \\
\text { WsPIITg__6IG699-wgD9sNYACIOmhDR }\end{array}$ \\
\hline Video & Odiya & $\begin{array}{l}\text { https://www.youtube.com/watch?v=kFstQhYsRWs\&list=PL- } \\
\text { WsPIITg__TTWYKHCDcOwZIImX99i2\&index=2 }\end{array}$ \\
\hline Audio & Odiya & $\begin{array}{l}\text { https://www.youtube.com/watch?v=dTuJ5U96sn4\&list=PL-WsPIITgj_63Tw3f_W24KuxdZL7y- } \\
\text { Cny }\end{array}$ \\
\hline Audio & Hindi & $\begin{array}{l}\text { https://www.youtube.com/watch?v=66shymBnEjw\&list=PL-WsPIITgj_7y7f- } \\
\text { JHZOLeO483iTzwIMg\&index=1 }\end{array}$ \\
\hline
\end{tabular}

Table 4: Key Deliverables in the Project Samvad COVID-19 Supplementary Action Plan

\begin{tabular}{|l|l|}
\hline Key deliverable & Numbers \\
\hline Total number of COVID-19 layered reproductive, maternal and child health videos produced & 24 \\
\hline No. of COVID-19 layered reproductive, maternal and child health audios produced & 18 \\
\hline No. of videos produced for frontline health workers & 6 \\
\hline No. of frontline health workers oriented and sensitized & 918 \\
\hline No. of community viewership for videos & 283,866 \\
\hline No. of listenership for Interactive Voice Response System audio clips & 85,199 \\
\hline
\end{tabular}

$\mathrm{NCH}$ related communication during the acute phase of the pandemic without any communication breakdowns.

These dissemination approaches have been rolled out quite successfully as the documented listenership was recorded at 85,199 and content viewership at 283,866 during June-August 2020.

Using this approach, the project-team oriented and sensitized 918 state-level partners' FLW. They were trained on the use of WhatsApp and WhatsApp group creation for the dissemination of community videos during the emergency and their roles and responsibilities during the pandemic. The FLW also helped in collecting the mobile phone numbers of the families and helped them to connect with IVRS to receive health, nutrition, and COVID-19 related information over the telephone calls. Table 4 shows further details of the content and reach to the community as reflected in terms of viewership and listenership.

Later on, Project Samvad conducted a phone-based monitoring survey with FLW and the community members after the implementation was completed in September 2020 to understand the quality of dissemination during this period. The summary of Project Samvad's quality assurance survey is in Box 1. The summary shows that digital dissemination and orientation of the FLW during the pandemic worked effectively on the ground.

The key challenges during the initial months of the COVID-19 pandemic were to ensure that the project continued reaching communities and disseminating RMNCH messages without the physical presence in the field. The use of digital platforms was found to be the way forward, but the partners and the field functionaries had certain reservations such as capabilities of the FLW, process management, cost of devices, and internet to quickly shift to this new mode of dissemination. An adjacent challenge was to convince the partners to use these modes of dissemination for layered RMNCH and COVID-19 messaging when they were busy responding to the pandemic in other ways. After rounds of discussions, our partners agreed to take on digital channels as an approach to disseminate health information, understanding that continuing RMNCH messaging was critical for health and nutrition outcomes and the layering of COVID-19 messages supported their pandemic response. FLW were trained virtually to take the additional responsibilities using digital channels and disseminated the video content.

There are several unresolved challenges in the digital dissemination that the project experienced. One such challenge was the collection of the dissemination statistics to ensure the quality of the dissemination and also to guide the course correction in the process. It was hard to know if the content was viewed and if it was viewed to what extent it was understood and applied. Another issue was to ensure that the content is reaching its target audience. In the case of Project Samvad, the target audience was women of the reproductive age group. The third issue that the project experienced was to improve the engagement of the recipients with the content and also with the peers. In one-sided unidirectional pushing of the messages and video content, the project did not have data to reflect upon if this messaging had triggered discussion and engagement of the recipients 
on the content shared over IVRS and WhatsApp.

Even though there were challenges, project implementation during the pandemic opened up opportunities for innovating, learning, and achieving the goals. Below mentioned are some of the lessons that the team captured:

- WhatsApp proved to be a very useful tool for information dissemination in the rural context. This internetbased messaging platform is hugely popular and most of the FLW were already quite familiar with its basic functions and are using it to communicate with families, friends, and neighbors.

- The partners recognized the importance of WhatsApp and they took a keen interest in it as a virtual method of dissemination. This experience provided an opportunity to inspire and motivate them to invest in the use of virtual methods in regular community outreach services.

- As the use of WhatsApp makes a foray into the field activities, we learned that the partners found it useful for virtual dissemination, for supervisory activities, and periodic reviews of work.

- The importance of the audio and video materials has been acknowledged by the partners and is being used continuously for different purposes since then such as for orientation of the FLW, providing information, and alerting the community.

- Adopting virtual mode for information dissemination is not only low-cost but also enables reaching farther - to the most difficult to reach places, especially during the pandemic.

WhatsApp and IVRS were useful tools to reach out to the community, but due to the concerns around the use and access to mobile phones, and particularly smartphones, internet, and social media platforms by the rural communities, especially women, ${ }^{8}$ Project Samvad could also have used community radio to ensure the reach to the last mile and those who do not have access to even basic feature phone. ${ }^{9}$

\section{Box 1: Key findings of the quality assurance survey}

- $86 \%$ FLW watched self-learning videos on role of FLW during COVID-19.

- $72 \%$ FLW reported that generating awareness about taking precautions related to COVID-19 infection and motivating people to participate in WhatsApp group discussion were their key roles in this process.

- Out of all mediators and community members who watched or heard the messages, more than $90 \%$ of the mediators and almost $100 \%$ of community members found the messages useful.

- Videos on water, sanitation and hygiene were most watched (92\%), followed by infant and young child feeding (76\%), mother's diet (65\%), and family planning (58\%).

\section{MATERNAL AND CHILD HEALTH COMMUNICATION DURING THE PANDEMIC}

Upon evaluating all options, Project Samvad decided to deliver regular RMNCH messages layered with COVID-19 related awareness. The key consideration was to continue the communication on RMNCH because the public health system in the project locations was turning their attention to the pandemic and delivery of regular $\mathrm{RMNCH}$ services was getting affected. There have been studies that confirm similar observations related to the effects of the pandemic on the delivery of the services. ${ }^{10}$ In such a situation it was important to reach out to the community with the information that they needed. Past lessons from the Ebola outbreak in West Africa have taught us that crises of similar nature adversely affect the delivery of the services and continuation of the health communication that is valuable to the community. ${ }^{11}$ Health communication during such crises becomes more important because miscommunication and false information often dominate social media platforms and inflicts more harm to the people as they believe it in the absence of information from authentic sources. ${ }^{12}$ Project Samvad continued to provide emergency communication on the prevention of COVID-19 in addition to RMNCH messaging. The monitoring survey conducted by the project suggests a high degree of satisfaction from the community with the information received. Out of all mediators and community members who watched or heard the messages, more than $90 \%$ of the mediators and almost $100 \%$ of community members found the messages useful.

It is important to reach out to the community with messages that they can rely upon and use for their safety. This was made possible by using the virtual platforms and the power of the internet to reach out to the project beneficiaries promptly. Other studies also establish that digital dissemination and the use of social media have an important role in public health communication. Social media platforms helped in reinforcing the COVID-19 prevention measures while observing physical distance to check the spread of the virus. ${ }^{13}$

Such interventions must not stop suddenly after the project phase is over; a gradual phase-out should be practiced in a most sustainable and ethical manner. ${ }^{14}$ Under Project Samvad, after August 2020, the project activities related to digital dissemination did not stop, but rather they were scaled up in discussion with the partners and considering the importance of continuing such communication with communities and FLW. ${ }^{15}$ Project Samvad also proposed activities for institutionalization and capacity building of the partner organizations for the continuation of digital dissemination beyond the life cycle of the project.

\section{PARTNERS’ CAPACITY}

The lack of confidence among partner organizations in the use of digital and social media channels for dissemination of layered RMNCH and COVID-19 messages created some delay in initiating digital dissemination under Project Samvad. Project Samvad staff had concerns about the partners' in-house human resources and bandwidth amidst a pandemic to steer the process, skill gaps among the FLW and 
administrative staff, necessary hardware and other infrastructure to implement the approach, and the financial provisions and internet costs and access on an ongoing basis. There is documented evidence in the Indian context highlighting similar issues, such as cost, efficiencies, and the capacity of the providers as barriers to adopting digital tools to bring efficiencies in the delivery of health services. ${ }^{16}$ However, there was an urgent need to reach out to the communities. FLW became the driving force for the adoption of these channels for health communication during the pandemic. A greater acceptance among the partners has been observed with the usefulness and potential of digital technology in healthcare communication and information dissemination due to the influence of Project Samvad.

\section{ENGAGEMENT FOR BETTER HEALTH OUTCOMES}

The use of digital dissemination emphasized building the engagement of the users with the FLW and also among the users through allowing them to provide feedback, ask questions and clarifications, and share experiences both through IVRS and WhatsApp-based video dissemination platforms. This was done to improve the impact of the communication on the knowledge and behavior of the communities receiving the digital content. Evidence suggests that improved engagement results in better health outcomes. ${ }^{17}$ Some of the challenges to building effective engagement were related to limitations of the technological solution. There was no means to get the analytics of WhatsApp-based video dissemination to the community and make course corrections to improve the engagement. However, the project attempted to get data via follow-up questions and by encouraging the participants to reach out to the health workers for more information. Moving forward, the tech-based solution development may help to get the timely analytics of information to the program managers to take corrective actions to improve the program impact. The design of tools may help to improve the engagement of the communities for better health outcomes and impact. Identifying the engagement drivers based on psychological theory, co-creation, and validation of the intervention features with the people who will ultimately use them and measure and change based on the qualitative and quantitative feedback. ${ }^{18}$ Project Samvad conducted a round of telephone surveys to assess the engagement and perspectives of the providers and users.

\section{CONCLUSION}

In the future, while developing programs of similar nature and in similar settings, the development practitioners and policymakers may learn from the experience of Project Samvad during the initial months of the COVID-19 pandemic. To complement the work that Project Samvad did during the pandemic, context-specific other solutions such as hyper-local content creation and dissemination using community radios could also be used. To ensure the quality of the intervention, a standard protocol should be developed for scheduling the content dissemination, frequency, and follow-up questions. The digital dissemination can be automated using a chatbot, which can also be used to col- lect analytics to guide implementation. This would help in ensuring the quality of digital dissemination at a scale difficult to manage manually. In addition to this, replication of projects of similar nature should consider designing messages suiting the requirements of the channels used to disseminate them and include quality parameters such as messages disseminated and messages seen or read to continuously guide the process improvement. Telephone surveys with the beneficiaries can also be used to monitor the status of the video viewership and IVRS listenership. The principles of co-design and co-creation should be used to develop the program content and continuously monitor to improve it.

\section{ACKNOWLEDGMENTS}

We thank the United States Agency for International Development (USAID) India Mission, especially Mr. S Vijay Paulraj for his support. We also thank the Project Samvad partners at the state and district levels for supporting the implementation of the project, in particular during the challenging times posed by COVID-19. We thank Digital Green's Senior Leadership in India and Global Leadership Group for continuous support to this project and for providing strategic direction. We also thankfully acknowledge the contribution of frontline workers, who despite all kinds of challenges and hardship during the COVID-19 pandemic, worked tirelessly to implement the project activities and continue reaching beneficiaries with critical health messaging. Lastly, we acknowledge the support of everyone who, directly or indirectly, supported Project Samvad's work.

\section{DISCLAIMER}

This work is made possible by the generous support of the American people through the United States Agency for International Development (USAID). The content in this manuscript is the responsibility of Digital Green and does not necessarily reflect the views of USAID or the United States Government.

\section{FUNDING}

We duly acknowledge the funding from USAID via Agreement Number AID-386-A-15-00008 to implement Project Samvad.

\section{AUTHORSHIP CONTRIBUTIONS}

FA conceptualized the manuscript, developed the framework, and led the process of coordination and review with other authors. He wrote the first draft, edited the overall structure, flow, and logic of this manuscript, and finalized it for publication. SRC collected the information, reviewed the documents, and supported the collection of references. SK collected the data and input them in the tables and conducted fact checks. RP and SN also reviewed the manuscript and provided feedback. GB edited the manuscript to improve the expression and articulation and supported the process of incorporating reviewer feedback, along with FA. 
ST conducted final editing and review.

\section{COMPETING INTERESTS}

The authors completed the Unified Competing Interest form at www.icmje.org/coi disclosure.pdf and declare no conflicts of interest.

\section{CORRESPONDENCE TO:}

Farhad Ali, Master of Science in Public Health, Digital Green, Avanta Business Centre, Office no. 1208, 12th Floor, Ambadeep Building, KG Marg, Connaught Place, New Delhi 110001.farhad@digitalgreen.org

Submitted: February 24, 2021 GMT, Accepted: March 25, 2021 GMT 


\section{REFERENCES}

1. Unicef. UNICEF Data Warehouse. Published 2021. Accessed February 2, 2021. https://data.unicef.org/res ources/data explorer/unicef $\mathrm{f} /$ ?ag=UNICEF $\& \mathrm{df}=\mathrm{GLOB}$ AL DATAFLOW \&ver $=1.0 \& \mathrm{dq}=\mathrm{IND} . \mathrm{MNCH} \mathrm{MMR}+\mathrm{MN}$ CH_LTR_MATERNAL_DEATH+MNCH_MATERNAL_DE ATHS. . \&startPeriod=2000\&endPeriod $=2021$

2. Vora KS, Mavalankar DV, Ramani KV, et al. Maternal health situation in India: a case study. $J$ Health Popul Nutr. 2009;27(2):184-201. doi:10.3329/jh pn.v27i2.3363

3. Taneja G, Sridhar VSR, Mohanty JS, et al. India's RMNCH+A Strategy: approach, learnings and limitations. BMJ Glob Heal. 2019;4(3):e001162. doi:1 0.1136/bmigh-2018-001162

4. Brinkel J, Krämer A, Krumkamp R, May J, Fobil J. Mobile Phone-Based mHealth Approaches for Public Health Surveillance in Sub-Saharan Africa: A Systematic Review. Int J Environ Res Public Health. 2014;11(11):11559-11582. doi:10.3390/ijerph1111115 $\underline{59}$

5. India Brand Equity Foundation. RURAL INDIA DIGITIZATION - A BOX OF OPPORTUNITIES. Published 2020. https://www.ibef.org/blogs/rural-indi a-digitization-a-box-of-opportunities

6. Iqbal M. WhatsApp Revenue and Usage Statistics (2020). Business of Apps. Published 2021. https://ww w.businessofapps.com/data/whatsapp-statistics/

7. Sahni Heena SH. Role of social media during the COVID-19 pandemic: Beneficial, destructive, or reconstructive? Int J Acad Med. 2020;6(2):70-75. doi:1 0.4103/IJAM.IJAM_50_20

8. Mohan D, Bashingwa JJH, Tiffin N, et al. Does having a mobile phone matter? Linking phone access among women to health in India: An exploratory analysis of the National Family Health Survey. Joe W, ed. PLoS One. 2020;15(7):e0236078. doi:10.1371/jour nal.pone. 0236078

9. Unicef. Community radio joins the fight against COVID-19 in Timor-Leste. Unicef Timor Leste. Published 2020. https://www.unicef.org/timorleste/st ories/community-radio-joins-fight-against-covid-1 9-timor-leste
10. Chandrashekar VS, Sagar A. Impact of COVID 19 on India's family planning program, policy brief. Published online May 2020.

11. Strong AE, Schwartz DA. Effects of the West African Ebola Epidemic on Health Care of Pregnant Women: Stigmatization With and Without Infection. Published online 2019:11-30. doi:10.1007/978-3-31 9-97637-2_2

12. Roberts H, Seymour B, Fish SA, Robinson E, Zuckerman E. Digital Health Communication and Global Public Influence: A Study of the Ebola Epidemic. J Health Commun. 2017;22(sup1):51-58. do $\mathrm{i}: 10.1080 / 10810730.2016 .1209598$

13. Budd J, Miller BS, Manning EM, et al. Digital technologies in the public-health response to COVID-19. Nat Med. 2020;26(8):1183-1192. doi:10.10 38/s41591-020-1011-4

14. Hunt M, Eckenwiler L, Hyppolite SR, Pringle J, Pal N, Chung R. Closing well: national and international humanitarian workers' perspectives on the ethics of closing humanitarian health projects. J Int Humanit Action. 2020;5(1):16. doi:10.1186/s41018-020-0008 $\underline{2-4}$

15. National Academy of Sciences. Healthy, Resilient, and Sustainable Communities After Disasters: Strategies, Opportunities, and Planning for Recovery.

16. Gulavani SS, Kulkarni RV. Role of information technology in health care. Proc 4th Natl Conf INDIACom-2010. 2010;36(1). http://www.ncbi.nlm.ni h.gov/pubmed/20097633

17. Litchman ML, Edelman LS, Donaldson GW. Effect of diabetes online community engagement on health indicators: Cross-sectional study. J Med Internet Res. 2018;20(4). doi:10.2196/diabetes.8603

18. Yeager CM, Benight CC. If we build it, will they come? Issues of engagement with digital health interventions for trauma recovery. mHealth. 2018;4:37. doi:10.21037/mhealth.2018.08.04 